\title{
Seroprevalencia de infección por virus de la hepatitis B y por virus de la inmunodeficiencia humana en una población de pacientes con múltiples transfusiones en cuatro hospitales, Colombia, Sur América
}

\author{
Mauricio Beltrán1, María Cristina Navas², María Patricia Arbeláez³ , Jorge Donado4, \\ Sergio Jaramillo ${ }^{4}$, Fernando De la Hoz ${ }^{1,5}$, Cecilia Estrada ${ }^{6}$, Lucía del Pilar Cortés ${ }^{7}$, \\ Amalia de Maldonado ${ }^{8}$, Gloria Rey ${ }^{1}$, Grupo Epiblood Colombia. \\ 1 Red Nacional de Bancos de Sangre, Instituto Nacional de Salud, Bogotá, D.C., Colombia \\ 2 Grupo de Gastrohepatología, Facultad de Medicina, Universidad de Antioquia, Medellín, Colombia \\ 3 Grupo de Epidemiología, Universidad de Antioquia, Medellín, Colombia \\ ${ }^{4}$ Banco de Sangre, Hospital Pablo Tobón Uribe, Medellín, Colombia \\ 5 Facultad de Salud Pública, Universidad Nacional de Colombia, Bogotá, D.C., Colombia \\ ${ }^{6}$ EPS Seguro Social, Medellín, Colombia \\ 7 Banco de Sangre, Instituto Nacional de Cancerología, Bogotá, D.C., Colombia \\ ${ }^{8}$ EPS Seguro Social, Bogotá, D.C., Colombia
}

Introducción. Aunque la transfusión de componentes sanguíneos es una terapia ampliamente utilizada, representa un riesgo de transmisión de agentes infecciosos.

Objetivo. Como parte de la iniciativa sobre sangre segura promovida por la Organización Panamericana de la Salud, se realizó un estudio para estimar la seroprevalencia de infección por virus de la inmunodeficiencia humana y virus de la hepatitis $B$ en pacientes con múltiples transfusiones en Colombia.

Materiales y métodos. Entre febrero y septiembre de 2003, se llevó a cabo un estudio transversal de 500 pacientes con múltiples transfusiones, seleccionados en cuatro hospitales de las ciudades de Bogotá y Medellín. Las muestras de suero obtenidas se analizaron por inmunoensayo con estuches comerciales.

Resultados. La frecuencia de seropositividad para el virus de la inmunodeficiencia humana fue de $1,8 \%$, (IC95\% 0,5-3,1). La frecuencia de seropositividad para el virus de la hepatitis B fue de 18,6\% (IC95\% 15,1-22,1). Los principales factores de riesgo fueron: recibir más de 48 unidades de sangre o componentes, tener diagnóstico de hemofilia, recibir transfusiones por un período mayor de un año, recibir sangre total, tener coinfección por virus de la hepatitis $\mathrm{C}$ y haber sido transfundido antes de 1993.

Conclusiones. Este es el primer estudio epidemiológico realizado en Colombia con un número significativo de pacientes con múltiples transfusiones. El hallazgo más relevante es la elevada prevalencia de infección por virus de la hepatitis B y virus de la inmunodeficiencia humana observado en la población de hemofílicos, comparado con los otros cuatro grupos de pacientes con múltiples transfusiones.

Palabras clave: transfusión sanguínea, VIH, virus de la hepatitis $\mathrm{B}$, factores de riesgo, Colombia

Seroprevalence of hepatitis B virus and human immunodeficiency virus infection in a population of multiply-transfused patients in Colombia

Introduction. Although the transfusion of blood products is a common therapy, it carries risk of transmission of infections, especially hepatitus B virus (HBV) and human immunodeficiency virus (HIV).

Objective. As part of the blood safety initiative, the Pan American Health Organization supported studies to estimate the prevalence of human immunodeficiency virus and hepatitis B virus infection in Colombia. 


\begin{abstract}
Materials and methods. Between February and September 2003, a cross sectional study examined 500 multiply-transfused patients at four hospital centers in the cities of Bogotá and Medellín. The serum samples were analyzed by enzyme immunoassay (EIA) using commercial kits.

Results. The seroprevalence of HIV infection was 1.8\% (CI 95\% 0.5-3.1). The seroprevalence of HBV infection was 18.6\% (Cl 95\% 15.1-22.1). Six risk factors were associated with HIV and HBV infection: (1) receiving more than 48 units of blood or blood components, (2) diagnosis of hemophilia, (3) receiving transfusions for more than one year, (4) receiving whole blood, (5) coinfection with hepatitis $C$ virus and (6) receiving transfusions before 1993.

Conclusions. This is the first epidemiological study with a significant sample size performed in multiply-transfused patients in Colombia. The principal finding was the high prevalence of HBV and HIV infection in patients with diagnosis of hemophilia compared with the other five groups of multiply-transfused patients.
\end{abstract}

Key words: Blood transfusion, HIV, hepatitis B virus, risk factors, Colombia

La transfusión sanguínea es una importante alternativa terapéutica. Sin embargo, también representa un riesgo biológico para las diferentes infecciones transmisibles por transfusión. Los principales agentes asociados con este tipo de infecciones son: el virus de inmunodeficiencia humana $(\mathrm{VIH})$, el virus de la hepatitis $\mathrm{B}$, el virus de la hepatitis C, Trypanosoma. cruzi, Treponema pallidum y especies de Plasmodium, entre otros $(1,2)$.

La transmisión por transfusión es muy eficaz para agentes como el $\mathrm{VIH}$, el virus de la hepatitis B y el virus de la hepatitis C, y oscila entre $75 \%$ y $100 \%$ en receptores de sangre contaminada (3). EI VIH y el virus de la hepatitis B se consideran los principales agentes asociados con las infecciones transmisibles por transfusión, lo cual se soporta por su amplia distribución y prevalencia en algunas zonas geográficas (2).

Para el año 2006, se estima en el mundo un total de 39,5 millones (rango, 34,1 a 47,1 millones) de personas con infección por el VIH. En América Latina se registraron 140.000 nuevos casos de infección y 65.000 muertes por sida (4).

En Colombia, para el 2005, la prevalencia de infección en la población general de 15 a 49 años se estimó entre $0,6 \%$ y $0,7 \%$, lo que representa

\footnotetext{
Correspondencia:

Mauricio Beltrán, Instituto Nacional de Salud, Calle 26 № 51-20, CAN, zona 6, Bogotá, D.C., Colombia.

Telefax: (571) 2207700

mbeltrand@ins.gov.co..

Recibido: 06/06/08; aceptado:16/12/08
}

160.000 personas, aproximadamente. La distribución de los casos de infección por el VIH, muestra una concentración en Bogotá, Antioquia, Valle, Atlántico, Risaralda, Santander y Norte de Santander, que dan cuenta de más del $80 \%$ del acumulado histórico de casos $(5,6)$.

La infección por el virus de la hepatitis B tiene una distribución mundial; se estima que existen más de 2.000 millones de personas, de los cuales, cerca de 360 millones están crónicamente infectados y con riesgo de enfermedad y muerte por cirrosis, por carcinoma hepatocelular o por ambas; se estima que estas hepatopatías causan entre 500.000 y 700.000 muertes cada año en el mundo (7).

Aunque Centroamérica y Suramérica se consideran regiones de baja endemia, los países presentan un amplio rango de prevalencia; además, esta región incluye la cuenca amazónica que comparten Perú, Brasil, Colombia y Venezuela, reconocida como una región de muy alta endemia (8). En Latinoamérica, se calcula que existen, aproximadamente, seis millones de infectados crónicos (8).

Colombia presenta una endemia moderada para la hepatitis $B$, aunque no se puede asignar un solo patrón epidemiológico para el territorio, dadas las diferencias geográficas, étnicas, culturales y de nivel socioeconómico (8).

La tasa de incidencia nacional para la infección por el virus de la hepatitis B para los años 2003 a 2006, ha oscilado entre 3,7 y 2,19 por 100.000 habitantes. Según los datos del 
2006, los departamentos de alta endemia son Guaviare, Guainía y Vaupés; los departamentos de endemia intermedia, Arauca, Bolívar, Caldas, Norte de Santander y Tolima, y el resto del territorio nacional corresponde a departamentos de baja endemia. La mayor proporción de casos se presentó en individuos de 15 a 44 años, lo cual sugiere transmisión por vía sexual y exposición ocupacional (9-11).

El VIH y el virus de la hepatitis B comparten las rutas de transmisión sexual, vertical y parenteral, por contacto con sangre y fluidos corporales contaminados. Los usuarios de drogas intravenosas, individuos con prácticas sexuales de riesgo y pacientes sometidos a múltiples transfusiones o hemodiálisis, constituyen las poblaciones con mayor riesgo de adquirir una infección por estos virus (8). La probabilidad de adquirir el virus por transfusión, aumenta con el número de unidades transfundidas, tiempo de exposición a las transfusiones, número de donantes de los cuales se recibe sangre o componentes y calidad de la tamización (12).

Para el año 2002, la Organización Mundial de la Salud (OMS) estimó que entre $5 \%$ y $10 \%$ de las infecciones por el VIH fueron transmitidas por transfusión. Se estima, además, que cada año, las transfusiones e inyecciones inseguras explicarían entre 8 y 16 millones de casos de infecciones por virus de la hepatitis B, 2,3 a 4,7 millones de infecciones por virus de la hepatitis C y 80.000 a 160.000 infecciones por $\mathrm{VIH}$, en el mundo $(13,14)$.

A nivel mundial, la tamización para el virus de la hepatitis B se inició en la década de los años 70, mientras que, en 1985, varios países iniciaron la tamización para el $\mathrm{VIH}$; sin embargo, en la década de los años 90 varios casos de infección por VIH por transfusión llevaron al establecimiento de diferentes medidas de control en los bancos de sangre, como el mejoramiento en el reclutamiento, en la selección de donantes y nuevas técnicas de tamización, que llevaron a una reducción importante del riesgo de transmitir por transfusión el $\mathrm{VIH}$, el virus de la hepatitis $\mathrm{B}$ y el virus de la hepatitis $C$ en la década de los 90 (15-17). Con las técnicas recientes de biología molecular para la detección del genoma viral, en particular, las pruebas de amplificación de ácidos nucleicos (nucleic acid amplification technology, NAT), el riesgo residual estimado se redujo sustancialmente (18-20).

En Colombia, los factores de riesgo que favorecen las infecciones transmisibles por transfusión han disminuido drásticamente gracias a que las pruebas de tamización se hicieron obligatorias en 1981 para el virus de la hepatitis B y, en 1991, para el VIH. Por otro lado, la donación de sangre por reposición pasó de $80 \%$ en 1999 a 50\% en 2006 y la cobertura de tamización para VIH, virus de la hepatitis $B$ y virus de la hepatitis $C$ pasó de 99 a 100\%. La transfusión de sangre total pasó de $15 \%$ en 1999 a $5 \%$ en 2006. La prevalencia de infecciones en donantes se estima entre tres de cada 1.000 unidades para infección por VIH y cinco unidades de cada 1.000 para el virus de la hepatitis B y el virus de la hepatitis C (21-23).

Como parte de la iniciativa sobre sangre segura de la Organización Panamericana de la Salud (OPS), se realizó un estudio multicéntrico en 10 países latinoamericanos, incluida Colombia, para determinar la frecuencia de los marcadores serológicos de infección por virus de la hepatitis $C$, virus de la inmunodeficiencia humana $y$ virus de la hepatitis $B$, en pacientes con múltiples transfusiones. Los resultados de la seroprevalencia de infección por virus de la hepatitis $C$ del estudio multicéntrico, incluido el estudio en Colombia, se publicaron en el 2005 (Journal of Clinical Virology, 34 suplemento 2).

Enel presenteartículo se presentan los resultados de los marcadores serológicos de infección por VIH y virus de la hepatitis $B$, en una población de 500 pacientes con múltiples transfusiones de cuatro instituciones hospitalarias de las ciudades de Bogotá y Medellín, y un análisis exploratorio de los factores de riesgo asociados a las infecciones transmisibles por transfusión.

\section{Materiales y métodos}

\section{Tipo de estudio}

Entre febrero y septiembre de 2003, se llevó a cabo un estudio transversal en una población de pacientes con múltiples transfusiones de cuatro 
instituciones hospitalarias, de máximo nivel de atención, en Bogotá y Medellín.

Todos los métodos, procedimientos y los formularios de consentimiento fueron revisados y aprobados por los comités institucionales de ética de los hospitales y de la OPS, el Instituto Nacional de Salud y la Universidad de Antioquia.

\section{Muestra}

Se incluyeron 500 pacientes con múltiples transfusiones, número mínimo establecido en el protocolo de la OPS para el estudio multicéntrico sobre el impacto de las transfusiones en el riesgo de transmisión del virus de la hepatitis $C$, en el que el tamaño de la muestra se calculó en 602 pacientes, teniendo en cuenta los datos de prevalencia de infección por este virus en pacientes hemofílicos (19,3\%) presentados en el Consenso Colombiano de Hepatitis C de 1999. Para el cálculo se utilizaron los programas Star Cole (encuesta de prevalencia), Epi-Info 6.02 y Epidat 2.1.

La muestra se reclutó de dos hospitales de Bogotá (Clínica San Pedro Claver e Instituto Nacional de Cancerología) y dos hospitales de Medellín (Clínica León XIII y Hospital Pablo Tobón Uribe). Las entidades hospitalarias se seleccionaron teniendo en cuenta el nivel de complejidad (nivel 3, Seguro Social, Clínica San Pedro Claver, y nivel 4, Instituto Nacional de Cancerología y Hospital Pablo Tobón Uribe) y amplia cobertura en diferentes estratos socioeconómicos de la población.

Siguiendo el protocolo definido por la OPS, se definieron dos criterios de inclusión; primero, transfusión de, mínimo, 10 unidades o componentes sanguíneos en dos ocasiones diferentes $y$, segundo, presentar, por lo menos, uno de los siguientes cinco diagnósticos: hemofilia u otros trastornos de la coagulación, talasemia, anemia drepanocítica, neoplasia, insuficiencia renal con necesidad de hemodiálisis o pérdida sanguínea aguda.

El único criterio de exclusión fue presentar un diagnóstico previo de infección por virus de la hepatitis $\mathrm{C}$, considerando que el objetivo principal del estudio multicéntrico era determinar la prevalencia de infección por este virus. No se indagó por antecedentes de infección por virus de la hepatitis B o VIH en la población de estudio.

En su mayoría, los pacientes se convocaron por vía telefónica, utilizando la información consignada en los registros de los bancos de sangre de los hospitales. Quienes estuvieron de acuerdo en participar, fueron informados de los riesgos, beneficios y derechos de la participación y se les entregó una copia del consentimiento informado.

Los pacientes fueron entrevistados por personal calificado y entrenado; en la entrevista, se diligencióunformularioúnicoqueincluía:variables demográficas; variables de transfusión, como motivo de transfusión, número de transfusiones, componentes transfundidos; así como factores de riesgo asociados a infecciones de transmisión parenteral, como procedimientos quirúrgicos y odontológicos, tratamientos con objetos punzantes, tatuajes, perforaciones estéticas (piercing) y uso de drogas psicoactivas por vía intravenosa. El formulario se complementó con datos de la historia clínica.

Todas las encuestas fueron revisadas y validadas por los epidemiólogos del Instituto Nacional de Salud y de la Universidad de Antioquia. Los datos de los pacientes detectados como positivos en cualquiera de las pruebas realizadas, se notificaron a los sistemas de vigilancia de las autoridades de salud en cada ciudad, con el fin de proceder al seguimiento requerido en cada caso.

\section{Pruebas serológicas}

Las muestras de sangre recolectadas por venopunción en tubos secos, se sometieron a centrifugación; la fracción de suero se almacenó en alícuotas a $-70^{\circ} \mathrm{C}$. Las muestras fueron analizadas por inmunoensayo con estuches comerciales para la detección de anticuerpos contra VIH-1 y VIH-2 (HIV 1/2 gO, versión 3, Axsym, Abbott) y anticuerpos contra el antígeno central del virus de la hepatitis B (Core TM, Axsym, Abbott) y para la detección del antígeno de superficie del mismo (HbsAg V2, Axsym, Abbott). 
Los sueros positivos para los anticuerpos contra el VIH correspondieron a muestras reactivas para el ensayo HIV 1/2 gO, confirmadas por un segundo inmunoensayo realizado con el estuche Murex HIV-1.2.0 (Abbott). Los sueros reactivos en dos ensayos individuales para el antígeno de superficie para el virus de la hepatitis $B$ (HBsAg) fueron confirmados con la prueba de neutralización (HBsAg confirmatory, Abbott). Las muestras se analizaron en el laboratorio del Banco de Sangre del Hospital Pablo Tobón Uribe y en el Laboratorio de Virología del Instituto Nacional de Salud.

\section{Análisis estadístico}

La variable "desenlace" para la infección por virus de la hepatitis B correspondió a la positividad, al menos, para dos ensayos realizados por separado para el marcador de la proteína core del virus de la hepatitis B (anti-HBc). La variable "desenlace"paralainfecciónporVIHcorrespondió a la reactividad, tanto para el inmunoensayo HIV 1/2 gO como para el inmunoensayo Murex HIV1.2.0, observando las condiciones del protocolo establecidas por OPS/OMS. El número de unidades transfundidas se categorizó de acuerdo con la mediana en un número mayor o igual a 48 unidades transfundidas.

Como medida de asociación, se presenta el odds ratio (OR) con su intervalo de confianza del $95 \%$. Si había alguna celda con valor de cero, para los cálculos se adicionó una unidad a cada una de las celdas, y cuando estuvo indicado, se tomaron los valores de la prueba exacta de Fisher. Se usaron los programas Epi-info, versión 6.04, y SPSS, versión 12.0 (Chicago, IL). El nivel de significación estadística se estableció en 0,05\%.

\section{Resultados}

De los 500 pacientes participantes con múltiples transfusiones, $47,2 \%$ tenía diagnóstico de entidades oncológicas, seguidos por pacientes con diagnóstico de hemofilia, 18,0\%, pacientes sometidos a hemodiálisis, $16,4 \%$, pacientes con sangrado agudo, $15,6 \%$, y pacientes con drepanocitosis o talasemia, 2,8\% (cuadro 1).

La frecuencia de seropositividad para el VIH fue de 1,8\%, (IC95\% 0,5-3,1), que corresponde a nueve pacientes. La frecuencia de anticuerpos contra la proteína core del virus de la hepatitis B (anti-HBC) fue de 18,6\% (IC95\% 15,1-22,1) representada en 93 pacientes positivos. De estos 93 casos, 13 presentaron también el marcador de antígeno de superficie (HBsAg). De estos 13 casos, 5 pacientes tenían un diagnóstico de enfermedad oncológica, 4 de hemofilia y 4 de insuficiencia renal con necesidad de hemodiálisis.

Con respectoalgrupo de muestras con reactividad para el marcador anti-HBc y negativos para el marcador HBsAg (82 pacientes), la mayoría provenía de pacientes con diagnóstico de hemofilia $(30,5 \%)$ y enfermedades oncológicas (29\%); en menor proporción, pacientes con diagnóstico de insuficiencia renal con necesidad de hemodiálisis (15,8\%) y pérdida sanguínea aguda (17\%). La menor prevalencia para este marcador se observó en el grupo con diagnóstico de talasemia o anemia drepanocítica $(1,2 \%)$.

Al explorar la asociación entre los factores de riesgo y la seropositividad para $\mathrm{VIH}$, se encontró una asociación entre el diagnóstico de hemofilia y la seropositividad $(\mathrm{OR}=17,2) \quad(\mathrm{IC} 95 \% 3,17$ $123,8)$; igualmente, fueron variables asociadas con la seropositividad para el VIH: el recibir más de 48 unidades $(\mathrm{OR}=6,25)$ (IC95\% 1,35-32,46), el haber recibido transfusiones por un período mayor de un año $(\mathrm{OR}=8,96) \quad(\mathrm{IC} 95 \%$ 1,18$188,54)$ y recibir sangre total $(\mathrm{OR}=12,47)(\mathrm{IC} 95 \%$ 1,56-79,85). La administración de glóbulos rojos se presentó como un factor protector para la seropositividad $(\mathrm{OR}=0,16) \quad(\mathrm{IC95 \%} \quad 0,04-0,76)$ (cuadro 2).

El punto de corte de 48 para el número de unidades transfundidas corresponde al valor de

Cuadro 1. Grupos de pacientes con múltiples transfusiones según diagnóstico de base, Bogotá-Medellín, Colombia 2003.

\begin{tabular}{lrr}
\hline Grupos & $\mathbf{n}$ & $\%$ \\
\hline Hemofílicos & 90 & 18,0 \\
Hemodiálisis & 82 & 16,4 \\
Drepanocitosis / talasemia & 14 & 2,8 \\
Oncológicas & 236 & 47,2 \\
Pérdida por sangrado agudo & 78 & 15,6 \\
\hline
\end{tabular}


la mediana en la población de estudio; teniendo en cuenta que la variable no presentó una distribución normal, se optó por este valor.

Los factores de riesgo asociados con la seropositividad para el virus de la hepatitis B fueron: diagnóstico de hemofilia $(\mathrm{OR}=2,75)$
(IC95\% 1,59-4,77), recibir más de 48 unidades $(\mathrm{OR}=2,00) \quad(\mathrm{IC95} \%$ 1,19-3,35), o haber sido transfundido por un período mayor de un año $(\mathrm{OR}=1,84) \quad(\mathrm{IC95} \%$ 1,12-3,04). La transfusión de sangre total casi duplicó el riesgo $(\mathrm{OR}=1,99)$ (IC95\% 0,50-7,34), aunque dicha diferencia

Cuadro 2. Pacientes con múltiples transfusiones según factores de riesgo para la infección por VIH, Bogotá-Medellín, Colombia. 2003.

\begin{tabular}{|c|c|c|c|c|c|c|c|}
\hline \multirow[b]{2}{*}{ Factores de riesgo } & \multicolumn{7}{|c|}{ VIH } \\
\hline & $\mathbf{N}$ & $(+)$ & $\%$ & $(-)$ & $\%$ & OR & OR/IC $95 \%$ \\
\hline \multicolumn{8}{|l|}{ Grupos } \\
\hline Hemofílicos & 90 & 7 & 7,8 & 83 & 92,2 & 17,2 & $3,17-123,8$ \\
\hline \multicolumn{7}{|l|}{ Drepanocitosis } & $0,02-3,81$ \\
\hline O talasemia & 14 & 0 & 0,0 & 14 & 100 & $3,19^{*}$ & (inexactos) \\
\hline Neoplasias & 236 & 2 & 0,8 & 234 & 99,2 & 0,31 & $0,04-1,68$ \\
\hline Sangrado agudo & 78 & 0 & 0,0 & 100 & 100 & $0,52^{*}$ & $0,06-4,15$ \\
\hline \multicolumn{8}{|l|}{ Número de unidades } \\
\hline Más de 48 unidades & 125 & 6 & 4,8 & 119 & 95,2 & 6,25 & $1,35-32,46$ \\
\hline Hasta 48 unidades & 375 & 3 & 0,8 & 372 & 99,2 & & \\
\hline \multicolumn{8}{|l|}{ Tiempo de transfusión } \\
\hline Mayor de un año & 268 & 9 & 3,4 & 259 & 96,6 & $8,96^{*}$ & $1,18-188,54$ \\
\hline Menor o igual a un año & 232 & 0 & 0,0 & 232 & 100 & & \\
\hline \multicolumn{8}{|l|}{ Componentes transfundidos } \\
\hline \multicolumn{8}{|l|}{ Sangre total } \\
\hline $\mathrm{Si}$ & 13 & 2 & 15,4 & 11 & 84,6 & 12,47 & $1,56-79.85$ \\
\hline No & 487 & 7 & 1,4 & 480 & 98,6 & & \\
\hline \multicolumn{8}{|l|}{ Glóbulos rojos } \\
\hline $\mathrm{Si}$ & 439 & 5 & 1,1 & 434 & 98,9 & 0,16 & $0,04-0.76$ \\
\hline No & 61 & 4 & 6,6 & 57 & 93,4 & & \\
\hline \multicolumn{8}{|l|}{ Plasma Fresco Congelado } \\
\hline $\mathrm{Si}$ & 134 & 3 & 2,2 & 131 & 97,8 & 1,37 & $0,27-6,35$ \\
\hline No & 366 & 6 & 1,6 & 360 & 98,4 & & \\
\hline \multicolumn{8}{|l|}{ Plaquetas } \\
\hline $\mathrm{Si}$ & 187 & 2 & 1,1 & 185 & 98,9 & 0,47 & $0,07-2,54$ \\
\hline No & 313 & 7 & 2,2 & 306 & 97,8 & & \\
\hline \multicolumn{8}{|l|}{ Crioprecipitado } \\
\hline $\mathrm{Si}$ & 90 & 7 & 7,8 & 83 & 92,2 & 17,2 & $3,17-123,8$ \\
\hline No & 410 & 2 & 0,5 & 408 & 83,1 & & \\
\hline \multicolumn{8}{|l|}{ Liofilizado } \\
\hline $\mathrm{Si}$ & 75 & 6 & 8,0 & 69 & 92,0 & 12,23 & $2,61-64,16$ \\
\hline No & 425 & 3 & 0,7 & 422 & 99,3 & & \\
\hline \multicolumn{8}{|l|}{ Año de la transfusión } \\
\hline Luego de 1995 & 364 & 3 & 0,8 & 361 & 99,2 & 1,0 & - \\
\hline Entre 1993 y 1995 & 14 & 0 & 0,0 & 14 & 100 & $6,03^{*}$ & (incorrecto) \\
\hline Antes de 1993 & 122 & 6 & 4,9 & 116 & 95,1 & 6,22 & $1,36-31,93$ \\
\hline \multicolumn{8}{|l|}{ Infección por Hepatitis C } \\
\hline $\mathrm{Si}$ & 45 & 4 & 8,9 & 41 & 91,1 & 8,78 & $1,87-40,11$ \\
\hline No & 455 & 5 & 1,1 & 450 & 98,9 & & \\
\hline \multicolumn{8}{|l|}{ Infección por Hepatitis B } \\
\hline $\mathrm{Si}$ & 93 & 4 & 4,3 & 89 & 95,7 & 3,61 & $0,79-16,06$ \\
\hline No & 407 & 5 & 1,2 & 402 & 98,8 & & \\
\hline
\end{tabular}

* Se añadió 1 a cada casilla para efectos de cálculo 
no alcanzó la significación estadística por el escaso número de pacientes. El recibir factor liofilizado o crioprecipitado también se asoció con un mayor riesgo de infección por virus de la hepatitis $\mathrm{B},(\mathrm{OR}=3,06)(\mathrm{IC} 95 \%$ 1,71-5,46) y (OR=1,93) (IC95\% 1,09-3,41), respectivamente. La administración de glóbulos rojos se presentó también como un efecto protector contra la infección por virus de la hepatitis $B(O R=0,49)$
(IC95\% 0,26-0,95), al igual que la administración de plaquetas $(\mathrm{OR}=0,42) \quad(\mathrm{IC} 95 \% \quad 0,24-0,74)$ (cuadro 3).

Tanto para la infección por el VIH como para la infección por el virus de la hepatitis $\mathrm{B}$, el recibir transfusiones antes de 1993 estuvo fuertemente asociado $(\mathrm{OR}=6,22)(\mathrm{IC} 5 \% 1,36-31,93)$ y $(\mathrm{OR}=2,78)$ (IC95\% 1,66-4,63), respectivamente. Si se com-

Cuadro 3. Pacientes con múltiples transfusiones según factores de riesgo para la infección por VHB. Bogotá-Medellín, Colombia.

\begin{tabular}{|c|c|c|c|c|c|c|c|}
\hline \multirow[b]{2}{*}{ Factores de riesgo } & \multirow[b]{2}{*}{$\mathrm{N}$} & \multirow[b]{2}{*}{$(+)$} & \multirow[b]{2}{*}{$\%$} & \multirow[b]{2}{*}{$(-)$} & \multicolumn{3}{|c|}{ VHB } \\
\hline & & & & & $\%$ & OR & OR/IC 95\% \\
\hline \multicolumn{8}{|l|}{ Grupos } \\
\hline Hemofílicos & 90 & 30 & 33,3 & 60 & 66,7 & 2,75 & $1,59-4,77$ \\
\hline Diálisis renal & 82 & 18 & 22,0 & 64 & 78,0 & 1,29 & $0,69-2,39$ \\
\hline \multicolumn{8}{|l|}{ Drepanocitosis } \\
\hline o talasemia & 14 & 1 & 7,1 & 13 & 92.9 & 0,33 & $0,02-2,49$ \\
\hline Neoplasias & 236 & 37 & 15,7 & 199 & 84.3 & 0,69 & $0,42-1,12$ \\
\hline Sangrado agudo & 78 & 7 & 9,0 & 71 & 91,0 & 0,38 & $0,17-0,87$ \\
\hline \multicolumn{8}{|l|}{ Número de unidades } \\
\hline Más de 48 unidades & 125 & 34 & 27,2 & 91 & 72,8 & \multirow[t]{2}{*}{2,0} & \multirow[t]{2}{*}{$1,19-3,35$} \\
\hline Hasta 48 unidades & 375 & 59 & 15,7 & 316 & 84,3 & & \\
\hline \multicolumn{8}{|l|}{ Tiempo de transfusión } \\
\hline Mayor de un año & 268 & 61 & 22,8 & 207 & 77,2 & \multirow[t]{2}{*}{1,84} & \multirow[t]{2}{*}{$1,12-3,04$} \\
\hline Menor o igual a un año & 232 & 32 & 13,8 & 2 & 86,2 & & \\
\hline \multicolumn{8}{|l|}{ Componentes transfundidos } \\
\hline \multicolumn{8}{|l|}{ Sangre total } \\
\hline $\mathrm{Si}$ & 13 & 4 & 30,8 & 9 & 69,2 & \multirow[t]{2}{*}{199} & \multirow[t]{2}{*}{$0,50-7,34$} \\
\hline No & 487 & 89 & 18,3 & 398 & 81,7 & & \\
\hline \multicolumn{8}{|l|}{ Glóbulos rojos } \\
\hline $\mathrm{Si}$ & 439 & 75 & 17,1 & 364 & 82,9 & \multirow[t]{2}{*}{0,49} & \multirow[t]{2}{*}{$0,26-0,95$} \\
\hline No & 61 & 18 & 29,5 & 43 & 70,5 & & \\
\hline \multicolumn{8}{|l|}{ Plasma Fresco Congelado } \\
\hline $\mathrm{Si}$ & 134 & 25 & 18,7 & 109 & 81,3 & \multirow[t]{2}{*}{1,01} & \multirow[t]{2}{*}{$0,58-1,73$} \\
\hline No & 366 & 68 & 18,6 & 298 & 81,4 & & \\
\hline Plaquetas & & & & & & & \\
\hline $\mathrm{Si}$ & 187 & 21 & 11,2 & 166 & 88,8 & 0,42 & $0,24-0,74$ \\
\hline No & 313 & 72 & 23,0 & 241 & 77,0 & & \\
\hline Crioprecipitado & & & & & & & \\
\hline $\mathrm{Si}$ & 90 & 25 & 27,8 & 65 & 72,2 & 1,93 & $1,09-3,41$ \\
\hline No & 410 & 68 & 16,6 & 34 & 83,4 & & \\
\hline Liofilizado & & & & & & & \\
\hline $\mathrm{Si}$ & 75 & 27 & 36,0 & 48 & 64,0 & 3,06 & $1,71-5,46$ \\
\hline No & 425 & 66 & 15,5 & 359 & 84,5 & & \\
\hline Año de transfusión & & & & & & & \\
\hline Luego de 1995 & 354 & 51 & 14,4 & 313 & 86,0 & 1,0 & - \\
\hline Entre 1993 y 1995 & 14 & 4 & 28,6 & 10 & 71,4 & 2,45 & $0,62-8,95$ \\
\hline Infección por Hepatitis C & & & & & & & \\
\hline $\mathrm{Si}$ & 45 & 19 & 42,2 & 26 & 57,8 & 3,76 & $1,88-7,53$ \\
\hline No & 455 & 74 & 16,3 & 381 & 83,7 & & \\
\hline Infección por VIH & & & & & & & \\
\hline $\mathrm{Si}$ & 9 & 4 & 44,4 & 5 & 55,6 & 3,61 & $0,79-16,06$ \\
\hline No & 491 & 89 & 18,1 & 402 & 81,9 & & \\
\hline
\end{tabular}


para la frecuencia de infección antes de 1993 y después de 1995, la reducción absoluta del riesgo para la infección por el VIH fue de 4,1\%, pasando de un riesgo de $4,9 \%$ a $0,8 \%$ y, para hepatitis $\mathrm{B}$, la reducción fue de $16,7 \%$, pasando de $31,1 \%$ a $14,4 \%$ (cuadros 2 y 3 ). Los datos anteriores equivalen a un descenso de $84 \%$ y de $46 \%$, respectivamente.

El análisis del riesgo según el periodo de transfusión (antes de 1993, entre 1993 y 1995, y después de 1995) representa un parámetro arbitrario relacionado con la legislación de la tamización de unidades y componentes sanguíneos en el país y no tiene relación con el volumen de unidades recibidas por una población en particular.

El análisis de los factores de riesgo, como procedimientos quirúrgicos y odontológicos, tratamientos con objetos punzantes, tatuajes, piercing y uso de drogas psicoactivas por vía intravenosa, no mostró asociación estadística con el estado de seropositividad para $\mathrm{VIH}$ o el virus de la hepatitis $B$.

\section{Discusión}

En el presente estudio realizado en las dos principales ciudades de Colombia con una muestra de 500 pacientes con múltiples transfusiones, se encontró una prevalencia de infección pasada o reciente por el virus de la hepatitis $B$ de $18,6 \%$ y, por el $\mathrm{VIH}$, de $1,8 \%$.

Los principales factores que se asociaron con el riesgo de infección por el virus de la hepatitis B y el VIH fueron: recibir más de 48 unidades de sangre o componentes, tener diagnóstico de hemofilia, recibir transfusiones por un período mayor de un año, recibir sangre total, tener infección concomitante por virus de la hepatitis C y haber sido transfundido antes de 1993. La administración de glóbulos rojos mostró un efecto protector contra la infección viral. Aunque es claro que el grupo con diagnóstico de hemofilia presenta el mayor riesgo, según la información obtenida no fue posible discriminar el riesgo atribuido a los diferentes componentes sanguíneos, en particular, porque los pacientes habían recibido más de un componente en la mayoría de casos. Esta misma situación se presentó en los demás grupos incluidos en el estudio.

Las prevalencias corresponden a una población de alto riesgo que presenta varios de los factores que se han asociado con aumento en la probabilidad de adquirir una infección transmisible por transfusión. Además, como se mencionó anteriormente, la eficacia de la transmisión por transfusión de $\mathrm{VIH}$ y virus de la hepatitis B es superior a $75 \%$ en pacientes que han recibido sangre contaminada (12).

Estudios recientes en pacientes con múltiples transfusiones, realizados en Argentina (24), Brasil (25), Cuba (26), Honduras (27), Perú (28) y Uruguay (29), mostraron prevalencias para $\mathrm{VIH}$ que oscilan entre $0 \%$ y $1,7 \%$, con Brasil $(1,7 \%$ ) y Perú $(1,4 \%)$ como los países que reportaron las prevalencias más altas. Respecto a la infección por el virus de la hepatitis $\mathrm{B}$, se hallaron valores entre $0,8 \%$ y $45,3 \%$; Cuba $(45,3 \%)$ y Perú $(39,9 \%)$ aportaron las mayores proporciones.

Los pacientes con diagnóstico de hemofilia, al tener una mayor exposición a los componentes sanguíneos, presentan un alto riesgo para ambas infecciones; en este estudio la asociación fue mayor para la infección por VIH, comparada con la asociación para el virus de la hepatitis $\mathrm{B}(\mathrm{OR}=17,2$ y 2,75 , respectivamente), ambas asociaciones con significación estadística, dado el número y diversidad de componentes transfundidos. No se encontró asociación con otros grupos de pacientes con múltiples transfusiones.

En dos estudios realizados en Cuba, uno en pacientes con tumores malignos y otro en pacientes con diagnóstico de enfermedades oncohematológicas, se halló una seroprevalencia de $\mathrm{HBsAg}$ de $1,8 \%$ y $9,3 \%$, respectivamente; según los autores, no se logró establecer relación entre la presencia del marcador de infección por virus de la hepatitis B y las variables relacionadas con la transfusión, posiblemente, debido a que estarían implicadas otras rutas de transmisión. En el presente estudio se describió una prevalencia de $2,6 \%$ en el grupo de pacientes con diagnóstico de enfermedades oncológicas $(30,31)$. 
Un estudio realizado en Brasil de 653 pacientes hemofílicos, permitió describir una prevalencia general de infecciones transmisibles por transfusión de $41,5 \%$, con tasas específicas para $\mathrm{VIH}$ de $13,3 \%$, de 2,9\% para virus de la hepatitis $B$, y de $39,4 \%$ para virus de la hepatitis C. Se halló, además, que $84,6 \%$ de los pacientes con infección por VIH presentaron infección concomitante por virus de la hepatitis $\mathrm{C}$, situación que se atribuye a que estos pacientes reciben mayor número de transfusiones 0 exposiciones a través de su vida y a que, en los países en desarrollo, pocas personas con hemofilia reciben un tratamiento adecuado, a pesar de que la provisión de concentrados de factores de la coagulación ha aumentado en los últimos años (32). En otro estudio en Brasil de 32 pacientes con múltiples transfusiones y con diagnóstico de beta-talasemia, se describió una prevalencia de $25 \%$ de infección por el virus de la hepatitis B y $6,3 \%$ por VIH (33). En el presente estudio, sólo se incluyeron 14 pacientes con diagnóstico de talasemia, de los cuales sólo uno, que corresponde a $7,1 \%$, presentó el marcador anti-HBc, mientras que todos fueron negativos para VIH.

Antes de 1995, en Colombia no había una buena cobertura de tamización de las unidades de sangre para la infección por VIH y virus de la hepatitis $\mathrm{B}$, lo cual explica las reducciones absolutas de $4,1 \%$ y $16,7 \%$, respectivamente, para aquellas personas transfundidas después de dicho año. Además, hay que tener en cuenta la disponibilidad de los componentes sanguíneos y la capacidad técnica para su obtención en el país en el periodo en mención.

Aunque un reducido número de pacientes fue transfundido con sangre total, se observó una asociación estadística significativa entre la transfusión de sangre total y la prevalencia de virus de la hepatitis $\mathrm{B}$ y $\mathrm{VIH}$; es de anotar que, en Colombia, la transfusión de sangre total ha disminuido de manera importante en el último decenio, lo que obedece a los programas de educación y sensibilización de las estrategias de sangre segura a nivel nacional (Instituto Nacional de Salud. Coordinación Nacional de Bancos de Sangre, 2006. Datos sin publicarse).
No se realizó análisis multivariado para ponderar la contribución de otros factores de riesgo diferentes a la transfusión sanguínea, dado que todos los pacientes incluidos en el estudio presentaban el antecedente de transfusión.

Aunque los programas de vacunación para el virus de la hepatitis B se instauraron a comienzos de la década de los 90 en recién nacidos y en ciertas poblaciones de alto riesgo, en el 2002 se había alcanzado una cobertura de $71,8 \%$ en la población infantil (34). En este estudio no se exploró el efecto protector de la vacuna, ya que esta información en la encuesta la brindaba el paciente y no se confirmaron ni el esquema completo de vacunación, ni el estado de inmunidad respectivo. El hecho de que $67,4 \%(337 / 500)$ de los pacientes con múltiples transfusiones refirieran no haber recibido la vacuna para el virus de la hepatitis $B$, sugiere que no se siguen adecuadamente los protocolos de manejo de estos pacientes y amerita una revisión de estas intervenciones.

En el pasado se han demostrado varios casos de infecciones transmisibles por transfusión por estos virus en algunos países latinoamericanos (México y Colombia) y, más recientemente, en Perú, generalmente asociados a inadecuada selección del donante y deficiencias en la tamización de estos agentes infecciosos (35-37). Actualmente, en Colombia la gran mayoría de casos de infección por estos virus corresponden a infecciones adquiridas por otras rutas, en particular, la vía sexual (14), situación que respalda la importancia de las estrategias de selección del donante que se vienen realizando y la reducción de la prevalencia de estas infecciones en donantes de sangre en el país $(23,38-40)$.

Las limitaciones del estudio son el diseño, el cual no permitió estimar el efecto de otros factores de riesgo asociados con la infección por virus de la hepatitis B y VIH diferentes a la transfusión sanguínea, y la baja frecuencia de algunas variables.

Aunque estos resultados no son extrapolables a la población de pacientes con múltiples transfusiones de las ciudades de Medellín y 
Bogotá, es importante mencionar que el estudio cuenta con un tamaño de muestra importante (500 pacientes) y se debe tener en cuenta el nivel de complejidad de las instituciones hospitalarias participantes, la calidad de los registros de éstas y la experiencia de sus equipos humanos. Además, es importante mencionar que el Instituto Nacional de Cancerología es la institución en el área de referencia a nivel nacional y que los otros hospitales, del Seguro Social, atienden un gran volumen de pacientes con diagnóstico de hemofilia y pacientes sometidos a hemodiálisis, según el plan de cobertura como entidad prestadora de salud.

Sin embargo, el estudio tiene algunas limitaciones como: la ausencia de muestreo aleatorio; no se comprobó el status serológico de inmunidad para la infección por el virus de la hepatitis B; existe un sesgo de memoria en la información obtenida de los pacientes; no se determinaron otros marcadores de infección por VIH y virus de la hepatitis $B$ para poder definir el tipo de infección y excluir falsos positivos y falsos negativos de las pruebas ELISA realizadas en el estudio.

El hecho de que la prevalencia de infección por el virus de la hepatitis $\mathrm{B}$ y VIH haya disminuido drásticamente en el grupo transfundido después de 1995, se explica por el incremento en la cobertura de tamización, el cual paso de $96 \%$ para $\mathrm{VIH}$ y $96,7 \%$ para virus de la hepatitis B, a 99,99\% para ambos marcadores, como se ha demostrado en el seguimiento de estas prevalencias (41).

Aunque no se evaluaron los anticuerpos contra el antígeno de superficie, es preocupante la baja cobertura de la vacunación para el virus de la hepatitis B observada en los cuatro grupos de pacientes con múltiples transfusiones, en especial, en aquéllos con enfermedades oncológicas, ya que éstos se encuentran en mayor riesgo de hepatitis $B y$, actualmente, no existen regulaciones para la vacunación.

En conclusión, éste es el primer estudio epidemiológico realizado en Colombia con un número significativo de pacientes con múltiples transfusiones. El hallazgo más relevante es la elevada prevalencia de infección por virus de la hepatitis B y VIH observada en la población de hemofílicos, en comparación con los otros tres grupos de pacientes con múltiples transfusiones.

\section{Agradecimientos}

Los autores agradecen a José Ramiro Cruz y a Serge Xueref, de la Organización Panamericana de la Salud, por la asesoría científica y estadística brindada durante todas las etapas del proyecto.

\section{Conflicto de intereses}

Los autores declaramos que no existen conflictos de intereses que puedan influir de manera alguna en los resultados presentados en este trabajo.

\section{Financiación}

El estudio fue financiado por la Organización Panamericana de la Salud a través de la Fundación Bill and Melinda Gates.

Grupo Epiblood Colombia: Mauricio Beltrán', María Cristina Navas ${ }^{2}$, María Patricia Arbeláez ${ }^{3}$, Jorge Donado ${ }^{4}$, Sergio Jaramillo ${ }^{4}$, Fernando De la $\mathrm{Hoz}^{1,5}$, Cecilia Estrada ${ }^{6}$, Lucía del Pilar Cortés $^{7}$, Gloria Barco ${ }^{4}$, Martha Luna ${ }^{6}$, Amalia de Maldonado ${ }^{8}$, Juan Carlos Restrepo ${ }^{2,4}$, Gonzalo Correa $^{2,4}$, Paula Borda ${ }^{1}$, Gloria Rey ${ }^{1}$, Marlén de Neira ${ }^{1}$, Ángela Estrada ${ }^{4}$, Sandra Yepes ${ }^{4}$, Gustavo Adolfo Uribe ${ }^{6}$, María Mercedes Muñoz ${ }^{8}$, Óscar Beltrán ${ }^{7}$, Javier Pacheco ${ }^{8}$, Iván Villegas ${ }^{9}$, Jorge Boshell ${ }^{1,10}$

1 Coordinación Nacional Red de Bancos de Sangre, Instituto Nacional de Salud, Bogotá, D.C.; ${ }^{2}$ Grupo de Gastrohepatología, Facultad de Medicina, Universidad de Antioquia, Medellín; ${ }^{3}$ Grupo de Epidemiología, Universidad de Antioquia, Medellín; ${ }^{4}$ Banco de Sangre, Hospital Pablo Tobón Uribe, Medellín; ${ }^{5}$ Facultad de Salud Pública, Universidad Nacional, Bogotá, D.C.; ${ }^{6}$ Instituto de los Seguros Sociales, Medellín; 7 Instituto de los Seguros Sociales, Bogotá, D.C.; ${ }^{8}$ Banco de Sangre, Instituto Nacional de Cancerología, Bogotá, D.C.; ${ }^{9}$ Instituto del Riñón, Medellín; ${ }^{10}$ Banco de Huesos y Tejidos, Fundación Cosme y Damián, Bogotá, D.C., Colombia. 


\section{Referencias}

1. Donegan E, Stuart M, Niland J. Infection with HIV-1 among recipients of antibody-positive donations. Ann Intern Med. 1990;113:733-9.

2. CentersforDiseaseControlandPrevention. Provisional public health service inter-agency recommendations for screening donated blood and plasma antibody to virus causing acquired immunodeficiency syndrome. MMWR Morb Mortal Wkly Rep. 1985;34:1-5.

3. Schreiber GB, Busch MP, Kleinman SH, Korelitz JJ. The risk of transfusion-transmitted viral infections. N Engl J Med. 1996;334:1685-90.

4. WHO/UNAIDS. Situación de la epidemia de SIDA. Programa Conjunto de las Naciones Unidas sobre el VIH/ SIDA y Organización Mundial de la Salud; Génova 2006. Fecha de consulta: 14 de enero de 2007. Disponible en: http://data.unaids.org/pub/GlobalReport/2006/200605F SLatinAmerica_es.pdf.

5. García R, Prieto F, Arenas C, Rincón J, Caicedo S, Rey G. Reducción de la transmisión madre hijo del VIH en Colombia: dos años de experiencia nacional, 20032005. Biomédica. 2005;25:547-64.

6. Ministerio de la Protección Social, Instituto Nacional de Salud. Prevalencia de VIH en población general Colombia 2003: VI Estudio Nacional Centinela de VIH 2003-2004. Inf Quinc Epidemiol Nac. 2004;9:363-4.

7. Lavanchy D. Worldwide epidemiology of VHB infection, disease burden, and vaccine prevention. J Clin Virol. 2005;34:S1-S3.

8. Shepard CW, Simard EP, Finelli L, Fiore AE, Bell BP. Hepatitis B virus infection: epidemiology and vaccination. Epidemiol Rev. 2006;28:112-25.

9. Ministerio de la Protección Social, Instituto Nacional de Salud. Situación hepatitis B en Colombia. Inf Quinc Epidemiol Nac. 2004;9:113-24

10. Ministerio de la Protección Social, Instituto Nacional de Salud. Comportamiento epidemiológico la hepatitis B, Colombia, 2005. Inf Quinc Epidemiol Nac. 2006;11:65-7

11. Ministerio de la Protección Social, Instituto Nacional de Salud. Hepatitis B. Inf Quinc Epidemiol Nac. 2006;11:297-312

12. Schmunis GA, Zicker F, Pinheiro F, Brandling-Bennett D. Risk for transfusion-transmitted infectious diseases in Central and South America. Emerg Infect Dis. 1998; 4: 5-11.

13. World Health Organization. World Health Day 2000: Information for National Blood Programmers. WHO Last Update September 2000. Fecha de consulta: 14 enero de 2007. Disponible en: http://www.euro.who.int/ mediacentre/PR/2000/2001090925

14. WHO/UNAIDS. Situación de la epidemia de SIDA. Programa Conjunto de las Naciones Unidas sobre el
VIH/SIDA y Organización Mundial de la Salud; Génova WHO/UNAIDS; 2006.

15. Busch M. HIV,HBV and HCV:Newdevelopments related to transfusion safety. Vox Sang. 2000;78(Suppl.2):253-6.

16. Dodd R. Germs, gels and genomes: A personal recollection of 30 years in blood safety testing. En: Stramer SI, editor. Blood safety in the millennium. Bethesda: American Association of Blood Bank; 2001. p. 97-122.

17. Pillonel J, Laperche S, Saura C, Desenclos JC, Couroucé AM. Transfusion-Transmissible Agents Working Group of the French Society of Blood. Trends in residual risk of transfusion-transmitted viral infections in France between 1992 and 2000. Transfusion. 2002;42:980-8.

18. Dodd RY, Notari EP, Stramer SL. Current prevalence and incidence of infectious diseases markers and estimated window-period risk in the American Red Cross blood donor population. Transfusion. 2002;42:975-9.

19. Velati C, Fomiatti L, Baruffi L, Romanò L, Zanetti A, Gruppo Italiano per lo Studio delle Malattie Trasmissibili con la Trasfusione. Impact of nucleic acid amplification technology (NAT) in Italy in the three years following implementation (2001-2003). Euro Surveill. 2005;102:12-4.

20. Alvarez do Barrio M, González Díez R, Hernández Sánchez JM, Oyonarte Gómez S. Residual risk of transfusion-transmitted viral infections in Spain, 19972002, and impact of nucleic acid testing. Euro Surveill. 2005;10:20-2.

21. Cortés A, Beltrán M, Olaya B, Hernández M. Riesgo de enfermedades infecciosas transmitidas por transfusión en el Valle del Cauca, Colombia. Colombia Médica. 1999;30:13-8.

22. Cortés A, Beltrán $M$, Olaya $B$, Hernández $M$. Epidemiología de la colección, proceso y uso de la sangre y componentes sanguíneos en el Valle del Cauca, Colombia. Colombia Médica. 1999;30:29-35.

23. Beltrán M, Jara J. Tamizaje de enfermedades infecciosas en bancos de sangre, Colombia 1995. Biomédica. 1997;17:137-42.

24. Remesar M, Gamba C, Kuperman S, Marcosa MA Miguez G, Caldarola S, et al. Antibodies to hepatitis C and other viral markers in multi-transfused patients from Argentina. J Clin Virol. 2005;34(Suppl.2):S20-6.

25. de Paula EV, Gonçales NS, Xueref S, Addas-Carvalho M, Gilli SC, Angerami RN, et al. Transfusion-transmitted infections among multi-transfused patients in Brazil. J Clin Virol. 2005;34 (Suppl.2):S27-32.

26. Ballester JM, Rivero RA, Villaescusa R, Merlín JC, Arce AA, Castillo D, et al. Hepatitis $C$ virus antibodies and other markers of blood-transfusion-transmitted infection in multi-transfused Cuban patients. J Clin Virol. 2005;34(Suppl.2):S39-46. 
27. Vinelli E, Lorenzana I. Transfusion-transmitted infections in multi-transfused patients in Honduras. J Clin Virol. 2005;34(Suppl.2):S53-60.

28. Laguna-Torres VA, Pérez-Bao J, Chauca G, Sovero $\mathrm{M}$, Blichtein $\mathrm{D}$, Chunga $\mathrm{A}$, et al. Epidemiology of transfusion-transmitted infections among multitransfused patients in seven hospitals in Peru. J Clin Virol. 2005;34(Suppl.2):S61-8.

29. López L, López P, Arango A, Rodríguez I, López J, Lima E, et al. Risk factors for hepatitis B and C in multi-transfused patients in Uruguay. $\mathrm{J}$ Clin Virol. 2005;34(Suppl.2):S69-74.

30. Neninger E, Velbes $\mathbf{P}$, del Castillo $\mathbf{C}$. Incidencia de infección por el virus de la hepatitis B y C. Rev Cubana Med. 2001;40:24-9.

31. Fontes EM, Amorim L, Carvalho SM, Farah MB. Hemophilia care in the state of Rio de Janeiro, Brazil. Rev Panam Salud Pública. 2003;13:124 -8.

32. Ustariz C, Rodríguez L, Delgado G, Ávila O, Gautier $\mathrm{H}$, Bencomo $\mathbf{A}$ et al. Frecuencia de hepatitis $\mathrm{B}$ y $\mathrm{C}$ en adultos con hemopatías malignas. Rev Cubana Hematol Inmunol Hemoter. 2005;21 ¿Páginas?.

33. Covas DT, Boturão NE, Zago MA. The frequency of blood-born viral infections in a population of multitransfused Brazilian patients. Rev Inst Med Trop Sao Paulo. 2006;35:271-3.

34. Ministerio de Salud, Instituto Nacional de Salud. Boletín epidemiológico semana SIVIGILA. Semana epidemiológica No. 42. Bogotá D.C.: Ministerio de Salud, Instituto Nacional de Salud; 2002.

35. Volkow P, Marín López A, Torres I. Plasma trade and the HIV epidemic. Lancet. 1997;349:327-8.

36. Sepúlveda J, del Río A, Valdespino JL, García L, Velázquez-Velazquez L, Volkow P. La estrategia de prevención de la transmisión del VIH/SIDA a través de la sangre y sus derivados en México. Salud Pública Mex. 1995;37:624-35.

37. A transfusion HIV prevention model for Perú. Transfusion Today. 2006;67:21-3. Fecha de consulta: 14 de enero de 2007. Disponible en: http://www.isbt-web.org/files/tt/ TT67.pdf

38. Beltrán M, Ayala M. Importancia de la encuesta de selección de donantes. Experiencia en un banco de sangre, Bogotá, Colombia, 1996. Biomédica. 2000;20:123-5.

39. Beltrán M, Ayala M, Palomino F. Seroprevalencia del virus de la hepatitis $C$ en el banco de sangre de un hospital de Bogotá, Colombia 1998. Medicina Transfusional al Día. 2001;1:15-7.

40. Gamarra G, Daza N, Díaz J, León C, Ramírez H. Prevalencia de enfermedades transfusionales en donantes del Banco de Sangre del Hospital Universitario Ramón González Valencia, 1994-1997. Med UIS. 1998;12:203-10.

41. Schmunis GA Cruz JR. Safety of the blood supply in Latin America. Clin Microbiol Rev. 2005;181:12-29. 